\title{
Cytomegalovirus Disease in Patient with HIV Infection
}

\section{EL Fane $\mathbf{M}^{1 *}$, Sodqi $\mathbf{M}^{1}$, EL Rherbi A $^{2}$, Chakib A ${ }^{1}$, Oulad Lahsen $A^{1}$, Marih $L^{1}$ and Marhoum EL Filali K ${ }^{1}$}

${ }^{1}$ Department of Infectious Diseases, CHU Ibn Rocd, Casablanca, Morocco

${ }^{2}$ Centre Poison Control and Pharmacovigilance Morocco, Rabat, Morocco

\section{Summary}

Cytomegalovirus (CMV) disease is a serious condition due to reactivation of previously latent infection or newly acquired infection, it occurs frequently in immunocompromised patients by HIV infection. Even it is actually uncommon in the developed nations with the widespread use of highly active antiretroviral therapy (HAART), CMV disease continues to be among the most common opportunistic infections in patient living with HIV (PLWH) in developing countries. Its severity is linked to its tropism for retina and central nervous system (CNS). It generally affects patients with major deficit in cellular immunity. It's also an important HIV cofactor that promotes the virus progression and influences morbidity and mortality in PLWH by maintaining immunity dysregulation as well as a chronic systemic inflammation. Retinitis is the major reported CMV disease in PLWH, followed by gastro-intestinal and CNS involvements, rarely lung can be also affected. Diagnosis is achieved by clinical examination; the gold standard is polymerase chain reaction (PCR) in blood and tissue samples. Unless an earlier and effective management, prognosis of CMV disease will be unfavorable. The standard treatment is based on the administration of systemic antiviral drugs. Maintenance treatment is strongly indicated in CMV retinitis to prevent relapses; whereas its indication is discussed in the other organ involvements.

Keywords: HIV infection; Cytomegalovirus; Retinitis; Colitis

\section{Introduction}

In developing countries, despite efforts made by public health programs to prevent and detect the HIV infection, the diagnosis is still late; which leads to a high rate of mortality due to opportunistic infections (OI) [1]. Cytomegalovirus (CMV) disease is a major debilitating OI in patients with advanced stage HIV-1 infection. Retinitis is the most common manifestation of the disease, which can result in total blindness if untreated [2] in spite of a well conducted antiCMV treatment, relapses were frequent and often due to drug-resistant strains of CMV [3]. Furthermore, the CMV infection is associated to HIV disease progression and remains a huge problem of care needing a multidisciplinary team (infectious disease specialist, ophthalmologist, gastroenterologist, neurologist, anatomical pathologist...), many paraclinical exams and very expensive treatment [4,5]. Good knowledge of the clinical features of the disease, the optimal use of available diagnostic tests and therapeutic schemes in force, is essential to improve the management of that redoubtable disease; however few articles treat this disease as a whole taking into consideration all its organic manifestations. The objective of this review is to fill this gap and provide a kind of practical guide to good management of this disease in its various manifestations organic.

\section{Epidemiology}

Before the era of High Active Antiretroviral Therapy (HAART), 30 to $40 \%$ of patients living with HIV (PLWH), develop a CMV disease [68]. Actually, there has been a marked decrease in the incidence of CMV retinitis, 8 per 10000 cases versus 23 per 10000 cases in the pre HAART. In United States the advent of HAART resulted in a decrease of $90 \%$ in the incidence of CMV retinitis [3]. The frequency is described to be low in the sub-Saharan Africa (inferior to 10\%). This can be explained by the high rate of early mortality and variable population susceptibility to develop a CMV disease [8,9]. In Morocco, Data concerning epidemiologic profile of CMV disease are lacking; there is a huge need of cohort studies in this field [1]. However, some small retrospective studies showed CMV retinitis incidence rates close to $4 \%$ that remains too low comparing to other African countries [8,9]. In south Asia, rates approaching 20 to $30 \%$ are noticed [10].

\section{Pathophysiology}

\section{Causal agent}

CMV or HHV-5 (type 5 of Human Herpes Virus) is a double-stranded DNA virus. It is the largest of the human herpes viruses with a $230 \mathrm{~kb}$ genome encoding 165 genes [11]. Its genome is protected by a capsid surrounded by an envelope coated with glycopeptides. It is widely present in general population and its prevalence is close to $50 \%$ in the countries of Western Europe and up to $90-100 \%$ in developing countries $[12,13]$.

\section{Contamination and dissemination}

CMV is an ubiquitous agent that can cause infection at any time during the course of life and commonly infects individuals from diverse geographical and socio-economic backgrounds [14]. Sexual transmission appears to be the most common route of infection in adults, though CMV can also be spread through oropharyngeal secretions, urine, breast milk, and blood $[11-13,15]$. The virus develops several strategies to evade the immune system and disrupt the inflammatory response to facilitate its dissemination. This leads to the persistence of the virus in the host throughout the life, mainly in endothelial cells, the stem cells of the bone marrow and peripheral blood monocytes $[13,16]$. During reactivation period, excretion of the virus in saliva and urine is a potential source of contamination [13]. Endothelial cells and monocytes, macrophages play a role in blood dissemination, whereas granulocytes favor CMV spread in tissues [15]. This virus has a particular tropism for retinal and sensorineural cells; the primary lesion is a vasculitis causing inflammation, thrombosis and necrosis $[17,18]$.

\section{Host defense}

The body's defense system against CMV infection is based on

*Corresponding author: EL Fane Mouna, Service des Maladies Infectieuses CHU Ibn Rocd, Casablanca, Morocco, Tel: +212 660832362; E-mail: elfanemouna@gmail.com

Received January 23, 2016; Accepted February 29, 2016; Published March 20 2016

Citation: EL Fane M, Sodqi M, EL Rherbi A, Chakib A, Oulad Lahsen A, et al (2016) Cytomegalovirus Disease in Patient with HIV Infection. J Antimicro 2: 108 doi: $10.4172 / 2472-1212.1000108$

Copyright: @ 2016 EL Fane M, et al. This is an open-access article distributed under the terms of the Creative Commons Attribution License, which permits unrestricted use, distribution, and reproduction in any medium, provided the original author and source are credited. 
HLA restricted cytotoxicity. Its proteins are degraded into peptides presented at the surface of the cell in association with the HLA class I. These infected cells are recognized and destroyed and specifically by CD8 cytotoxic T lymphocytes. Thus, CMV infection occurs almost exclusively during deficit of cellular immunity $[5,13]$.

\section{Interaction between CMV and HIV}

Several interactions seem to exist between CMV and HIV. HIV induces immunosuppression and facilitates all herpes viruses' development, including CMV. On the other hand, CMV promotes HIV pathogenicity, either by introducing into the cell its transactivation proteins, that activate also HIV proviral DNA, or by stimulating production of inflammatory cytokines which activate HIV DNA. Thus, CMV acts as a cofactor for HIV, with higher viral production and a more rapid progression to Acquired ImmunoDeficiency Syndrome (AIDS) [18]. Furthermore; a recently published issue (emery, et al.) suggests that the strong CMV association to inflammation and T-cell immune response skewing played a significant role in HIV disease progression in the early days of HIV epidemic [3]. Another African study conducted by Slyker, et al in 2009 reports a strong correlation between peak HIV viral load and peak CMV viral load [11].

\section{Clinical diagnosis}

\section{Conditions}

In PLWH, CMV infection characterizes the later stages of the disease. It occurs more commonly in patient with severe immunodeficiency with CD4 T lymphocytes count below $100 / \mu l$, patients are either not receiving ARV therapy or experiencing a therapeutic failure $[5,13,15]$. Besides, transplant recipients and patients who received an immunosuppressive therapy or those with congenital immune deficiency are also likely to develop the CMV diseases [5,19].

\section{Presentation}

Clinical manifestations of CMV infection in PLWH are slightly different from those observed in other conditions of immunosuppression. The clinical expression is progressive, often nonfebrile and the retinal involvement is the most common by $80 \%$ cases $[18,20]$. The other sites involved are entire gastro-intestinal tract (10 à 15\%), CNS (5 à 10\%) [6] and lungs (1 à 5\%) [18].

Retinal manifestations: CMV retinitis is the most frequently encountered OI in PLWH. Early stages of the infection are asymptomatic in $40 \%$ of cases [7]. Onset is insidious, and symptoms may include blurred vision, floaters, visual field defects, or other non specific visual complaints [5]. The diagnosis is based on the clinical examination and confirmed by positive blood cultures for CMV [5,8,21]. Dilated fundus exam with indirect ophtalmoscopy will show various types of active chorioretinal lesions including hemorrhagic patterns with an aspect of confluent area of full-thickness retinal necrosis with a yellowwhite granular appearance and associated retinal hemorrhages $[5,8]$. Ophthalmologic exam should be systematically and repeatedly carried out in PLWH, especially those with a too low CD4 T lymphocytes count $[2,5]$. In case of uncertain diagnosis, complementary Fluorescein Angiography shows beginning central hyperfluorescence which does not reach the edges of the lesion observed on funduscopic exam [22]. The infection has a very serious prognosis, both on the functional level (a short term risk of blindness) and the vital level [4-6]. Without treatment, CMV retinitis will become bilateral in $80 \%$ of cases and eventually will result in blindness from retinal atrophy, retinal detachment, or optic nerve involvement [5,8,21].

Gastrointestinal manifestations: The gastrointestinal (GI) tract is the second most common site of CMV infection. CMV involves entire GI tract, from the mouth to the anus. However, the colon remains the most frequently affected organ, the reason of this site predilection is not known $[19,23]$. Diagnosis of GI CMV disease is based on the following triad: clinical symptoms of GI disease, presence of characteristic lesions at endoscopy (ulcerations and erosions), and intra-nuclear or cytoplasmic inclusions at histological exams $[4,19,23]$.

CMV colitis: Colitis represents 5 to $10 \%$ of all clinical manifestations of CMV disease [23]. If frequently affects only the right colon necessitating full colonoscopy and multiples biopsies for accurate diagnosis. Clinical features are low grade fever, weight loss, anorexia, malaise, and abdominal pain, or diarrhea [5]. It may be responsible for severe complications, such as GI bleeding or perforation [24]. CMV can also induce colonic stricture presenting as acute intestinal obstruction [19]. The endoscopic appearance is made of a colonic inflammation with subepithelial edema and hemorrhage or of multiple small confluent ulcers, surrounded by a healthy mucosa [25]. These ulcers are consequences of ischemia and thrombosis caused by CMV vasculitis [18].

CMV Esophagitis: Esophagitis represents less than 5\% of CMV disease. It's the second most common GI manifestation after colitis. Clinical manifestations are dysphagia, odynophagia, substernal discomfort, nausea and vomiting [24-26]. Endoscopic features are multiple well-demarcated linear superficial ulcers usually located at the mid to distal position of the esophagus $[18,26]$. Its diagnosis requires multiple biopsies, which would find pathognomonic cytopathic effect of the CMV [24]. Less frequently, CMV may also be the cause of gastritis, Ménétrier's disease (protein-losing hypertrophic gastropathy) and ileitis [19].

Hepatitis, CMV cholangitis: These involvements are rare and mainly observed with disseminated CMV infection [27]. Liver damage often results in a moderate increase in seric activity of transaminases, sometimes associated to an increased serum bilirubin level. Liver biopsy and anatomopathologic examination will confirm diagnosis [5].

\section{Nervous System involvement}

Neurological complications have become extremely rare [28], they include many clinical manifestations [29]. The two main types are encephalitis and myelitis [18].

CMV encephalitis: The prevalence of CMV encephalitis is less than $2 \%$ in developed countries after the widespread use of HAART [28]. It often occurs in the context of disseminated CMV infection and manifests with impairement of cognitive functions $[18,29]$. In the context of resource-limited countries this condition remains under-diagnosed due to expensive diagnostic procedures. The study of cerebrospinal fluid (CSF) is slightly specific; it shows neutrophilic pleocytosis. Diagnosis is confirmed by a polymerase chain reaction (PCR) performed in CSF [18]. Imaging exams are nonspecific, however, ependymal involvement, which is characterized by ventriculitis aspect and a periventricular contrast enhancement, is very suggestive. The prognosis is extremely severe; hence a prompt diagnosis and an appropriate condition management are highly important [29].

Myeloradiculopathy: CMV-induced myeloradiculopathy of the terminal cone and cauda equina is also described during HIV infection. 
It can induce Guillain-Barre syndrome with urinary retention and ascending motor weakness of both lower limbs [30]. The study of CSF often shows a predominance of polynuclear or lymphocytes pleocytosis, a high protein level that can reach several grams. CSF glucose is low in about one-third of cases. Diagnosis is based on concomitant presence to these CSF disorders, of other systemic manifestations, and confirmed by virus-isolation tests in blood and/or CSF. The evolution of this condition is usually severe [31].

\section{Pneumonia}

Lung involvement is an uncommon expression of CMV infection in PLWH. Nevertheless, it remains the most common cause of viral pneumonia during HIV infection [32]. Hypoxemic diffuse interstitiel or alveolo-interstitial pneumonitis is the most common clinical presentation [29]. Co-infection with other bacterial, parasitic and fungal pathogen is common and makes CMV lung disease unclear [32,33]. Cytologic evaluation of respiratory secretions, bronchoalveolar lavage and tissue specimens, whereas low sensitive, may show characteristic lesions of CMV infection (Owl's -eye cells); CMV pneumonia can be diagnosed by isolation and identification of the pathogen through viral culture $[24,29]$. Lung involvement is a sign of wide viral dissemination; therefore it's associated to an elevated mortality rate $[29,32]$.

\section{Paraclinical diagnosis}

\section{Biological diagnosis}

Serology: Like other herpes viruses, CMV establishes lifelong latency following primary infection. Thus a positive antibody test is often not helpful to distinguish reactivation from latent infection $[14,34]$. It allows affirming a prior contact with the virus and therefore a potential risk of reactivation if lymphocytes count becomes low. If CMV serology is negative, it should be carried out once a year as long as CD4 count is below 200 cells/ $\mu \mathrm{l}$ [18]. Positive serology involves performing a PCR CMV before starting HAART if CD4 count is less than 100 cells/ $\mu \mathrm{l}$ [35]. It has also a preventive benefit in PLWH with negative anti CMV serology candidates for blood transfusion [20].

Polymerase chain reaction (PCR): Quantitative PCR testing is quicker and more sensitive than the CMV pp65 antigen assay $[5,16,34,36]$. PCR allow confirming the diagnosis of CMV retinitis by isolating viral genome removed from aqueous humor, the sensitivity of this technique is almost $100 \%$ [22]. The sensitivity and specificity of PCR for diagnosing CMV GI disease taking histology as the gold standard were respectively $85 \%$ and $95 \%$. Kishore, et al. concluded that PCR of rectal biopsy was the most sensitive method for detection of CMV in GI involvement [19]. This method is also particularly adapted to confirm CMV neurologic involvement for which the isolation and identification of CMV by PCR in CSF is a principal diagnosis criterion $[5,18]$.

\section{Histopathology}

The gold-standard for CMV detection is an examination of formalin-fixed, paraffin-embedded tissue, and immunohistochemistry (IHC). Histological examination is a relatively easy method but lacks sensitivity without IHC (10-87\%). Typical CMV inclusions on routine staining have "owl's eye" nuclear inclusions (Cowdry bodies) and eosinophilic inclusions in the cytoplasm of enlarged cells [19]. Retinal biopsy shows necrosis involving the entire neuro-epithelium and particularly pigmentary epithelium. The necrosis areas contain enlarged cells with intranuclear inclusions. Vascular sheathing is due to mononuclear cells infiltrates. Perivascular fibrosis is responsible for the vascular white cords feature [17]. Monoclonal antibodies Immunohistochemistry increases the sensitivity of histological examination [24].

\section{Prognosis}

Detectable CMV DNA in plasma or in whole blood is an independent predictor of death even after adjusting HIV RNA level or CD4 T cell count [11]. CMV disease is associated with a $60 \%$ increase in mortality among PLWH, likely due to the systemic character of the infection, the ability of CMV to transactivate HIV, and CMV's own intrinsic immunosuppressive effects [27,37]. CMV retinitis was associated with high rates of visual impairment and blindness [38]. The average period of progression to bilateral blindness was estimated at 21 months, even after CMV treatment initiation [27,37]. Rates of ocular complications, such as retinal detachment, and visual loss are substantially lower than those observed before the modern era and remain low even 10 years after CMV retinitis diagnosis [27,37,38]. Prognosis of CMV GI disease used to be unfavorable, the median survival reported in PLWH after CMV infection is 4 months with CMV colitis and 8 months after CMV esophagitis, even with ganciclovir therapy. Actually it's significantly improved with the utilization of HAART [23]. Other than visceral involvements, CMV may play a major role in the persistence of inflammatory phenomena and its contribution in atherosclerosis and premature ageing in PLWH has been highlighted by many studies reports $[11,18]$.

\section{Treatment}

CMV infection requires treatment with one of five currently available virostatic agents: ganciclovir (GCV), valganciclovir (VCV), foscarnet, cidofovir and fomivirsen. The choice of the antiviral agent and its route of administration is based on site and extension of CMV infection, potential drug's side effects, and the effectiveness of prior treatments $[18,39]$. In CMV retinitis, systemic administered therapy have an important benefit on mortality (50\% reduction), second-eye involvement (80\% reduction) and in the development of visceral disease (90\% reduction) when compared with local therapy only (intravitreal injections or implants) [38,40]. GCV, an inhibitor of CMV DNA polymerase, may be administred by intravenous (IV), oral, or intavitreal routes [19]. The most common side effect of GCV is neutropenia, which arises in $20 \%$ to $40 \%$ of patients and is reversible after drug withdrawn. The use of a sustained-release GCV implant placed directly into the vitreous cavity of the eye reduces both ocular relapses and systemic side effects of GCV, but it is not protective against involvement of the other eye or systemic CMV dissemination. Adverse effects associated to the GCV implant include decreased vision in the post-operative period and an increased risk of retinal detachment [39]. Valganciclovir (VCV) is a pro-drug of GCV and has good penetration into the vitreous cavity after oral administration. A positive response equivalent to GCV has been demonstrated. The adverse effects of both drugs are similar [39]. Foscarnet, an inhibitor of DNA polymerase and reverse transcriptase is administered intravenously. It can cause disturbance in mineral and electrolyte homeostasis as well as nephrotoxicity, both side effects are reversible after early discontinuation of the drug [19]. However, it is effective in the treatment of GCV-resistant retinitis [36]. Cidofovir acts by inhibiting CMV DNA polymerase. It does not require virusdependent phosphorylation for activation. It requires less frequent Intravenous administrations: once weekly for 2 weeks for induction therapy and once every 2 weeks for maintenance therapy thereafter. 
Citation: EL Fane M, Sodqi M, EL Rherbi A, Chakib A, Oulad Lahsen A, et al. (2016) Cytomegalovirus Disease in Patient with HIV Infection. J Antimicro 2: 108. doi:10.4172/2472-1212.1000108

Page 4 of 5

Nephrotoxicity is the most common dose- limiting cidofovir side effect, that may be prevented by intravenous rehydration with normal saline and administration of probenecid with each infusion [39]. Fomivirsen, is important and selective antiviral agent for CMV retinitis that is resistant to other antiviral agents. It acts by interfering with CMV mRNA encoding. The mode of administration is intravitreal injection. The various ocular toxic effects include uveitis, retinal pigment epitheliopathy, and bull's eye maculopathy [39].

\section{Initial therapy}

The first-line induction treatment of peripheral CMV retinitis is based on valganciclovir at a dose of $900 \mathrm{mg}$ PO q $12 \mathrm{hr}$ for 21 days. Intravenous GCV is reserved for patients with conditions that will disturb digestive absorption. In central CMV retinitis, or extended lesions, we can use either valganciclovir, IV GCV (5 mg/kg q12 hr) or foscarnet $(90 \mathrm{mg} / \mathrm{kg} \mathrm{q} 12 \mathrm{hr})$ $[15,35]$. GCV intravitreal injections, in association with valganciclovir $(900$ mg q12 hr) to avoid the occurrence of contralateral events, can also be used. Treatment efficacy was assessed by weekly Funduscopy exam should be weekly carried out to assess treatement efficacy and to indicate the shift to maintenance treatment when lesions scared over [18]. In placebo controlled study, GCV resulted in greater treatment success for CMV colitis in PLWH, improved endoscopic scores, and decreased dissemination of CMV disease. Foscarnet induced remission in $67 \%$ of patients who were unresponsive to GCV [19]. Shrestha et al suggested that GI disease requires an increased duration of therapy to decrease relapse risk. GCV $5 \mathrm{mg} / \mathrm{kg}$ $\mathrm{q} 12 \mathrm{hr}$ is given for 2 to 6 weeks, depending on therapy response. Viral load monitoring is becoming the cornerstone for tailoring drug therapy duration [34]. In case of CNS involvement, combinated GCV and foscarnet therapy is recommended $[6,16,18]$. Occurrence of a CMV viremia (PCR CMV exceeding 1000 copies) in PLWH result in an increased risk of CMV disease and ocular immune reconstitution syndrome (IRIS) requiring courses of systemic antiviral drug for two to three weeks without shifting to maintenance therapy $[35,36]$. The initiation of HAART in CMV disease should be delayed for at least 2 weeks in patients with CMV retinitis or other neurological disorder to prevent IRIS. If there is no evidence of CMV retinitis, HAART can be initiated simultaneously [19].

\section{Maintenance treatment}

Maintenance treatment is needed in the management of all CMV retinitis in order to prevent relapses as long as immunosuppression persists (CD4 lymphocytes count lower than $100 / \mu \mathrm{l}$ ) [18]. It is based on valganciclovir $900 \mathrm{mg}$ PO q day [6]. For other locations, the indication of prophylaxis should be discussed case by case [35].

\section{Primary prevention}

Early institution of HAART to restore CD4 counts in patients newly diagnosed with HIV infection and possibly preemptive GCV for CMV seropositive PLWH with low CD4 counts will reduce the bulk of HIV associated CMV disease. Early empiric IV GCV should be given pending histological and serological confirmation of diagnosis in suspected cases [34]. Vaccine trials have only been conducted in the western word but these have resulted in limited success. An effective CMV vaccine for prevention of congenital CMV infection is an increasing priority for the West, but the effects of a vaccine could also be far reaching in developing countries, particularly in PLWH [11].

\section{CMV infection and IRIS}

Immune Reconstitution Uveitis (IRU) may occur after the CMVspecific immunity restoration in PLWH on HAART. Time of onset is about six months after starting therapy in PLWH treated for CMV retinitis [18]. It is characterized by an increased inflammatory reaction in the anterior chamber or in the vitreous. IRU is resulting in several structural complications, such as the epiretinal membrane, retinal neovascularization or cystoid macular edema, which can quickly affect vision $[33,35,38]$. CMV encephalitis is also described in the literature in the form of an immune reconstitution ventriculitis in some patients [41].

\section{Conclusion}

CMV infection is a serious OI with a high mortality rate. It requires a systematic suspicion among immunocompromised patients for early diagnosis and appropriate management in order to avoid delayed treatment linked to an unfavorable mortality/morbidity scores.

\section{References}

1. Sodqi M, Marih L, Lahsen OA, Bensghir R, Chakib A, et al. (2012) Causes of death among $91 \mathrm{HIV}$-infected adults in the era of potent antiretroviral therapy. Presse Med 41: 386-390.

2. Mizushima D, Nishijima T, Yashiro S, Teruya K, Kikuchi Y, et al. (2015) Diagnostic Utility of Quantitative Plasma Cytomegalovirus DNA PCR for Cytomegalovirus End-Organ Diseases in Patients With HIV-1 Infection. J Acquir Immune Defic Syndr 68: 140-146

3. Emery VC (2015) Restimulating Interest in Cytomegalovirus as a Cofactor for HIV Infection. J Infect Dis 211: 169-171.

4. Gianella S, Massanella M, Richman D, Little SJ, Spina CA (2014) Cytomegalovirus Replication in Semen Is Associated with Higher Levels of Proviral HIV DNA and CD4+ T Cell Activation during Antiretroviral Treatment. J Virol 88: 7818-7827.

5. Haddad E (2000) L'infection à CMV chez les enfants immunodéprimés. JLE Médecine thérapeutique / Pédiatrie 3: 356-360.

6. Hantz S, Mazeron MC, Alain S, Leruez-Ville M (2009) Traitement des infections à cytomégalovirus humain (CMV). JLE Médecine thérapeutique 15: 211-222.

7. Jabs DA, Natta VML, Holbrook JT, Kempen JH, Meinert CL, et al. (2007) Longitudinal study of the ocular complications of AIDS. Ophthalmology 114: 780-786.

8. Lamzaf L, Ammouri W, Berbich O, Mezalek TZ, Adnaoui M, et al. (2011) Ocular complications of HIV infection: Experience of the Northern Excellence Pole of Morocco. J Fr Ophtalmol 34: 75-82.

9. El Mansouri Y, Zaghloul K, Himmich H, Amraoui A (1999) Ocular dammage in HIV infection. An epidemiological survey in the Casablanca Teaching Hospital (400 cases). Clinique 2044: 14-16.

10. Heiden D, Ford N, Wilson D, Rodriguez WR, Margolis T, et al. (2007) Cytomegalovirus retinitis: the neglected disease of the AIDS pandemic. Plos Med 4: 334.

11. Adland E, Klenerman P, Goulder P, Matthews PC (2015) Ongoing burden of disease and mortality from HIV/CMV coinfection in Africa in the antiretroviral therapy era. Front Microbiol 6: 1-9.

12. Descamps V (2014) Infection par le cytomégalovirus. Dermatologie infectieuse 27.

13. Mazeron MC, Alain S (2001) Infections à cytomégalovirus. EMC, Maladies Infectieuses 8-052-C-10: 18.

14. Fowotade A, Okonko OI, Agbede OO, Suleiman ST (2015) High seropositivity of $\operatorname{lgG}$ and $\operatorname{lgM}$ antibodies against cytomegalovirus (CMV) among HIV-1 seropositive patients in Ilorin, Nigeria. Afr Health Sci 15: 1-9.

15. Declerck L, Queyrel V, Morell-Dubois S, Dewilde A, Charlanne H, et al. (2009) Cytomegalovirus and systemic lupus: Severe infection and difficult diagnosis Rev Med Int 30: 789-793.

16. Fillet AM, Sénéchal B, Lehman CD, Cordonnier C (2000) Infection à cytomégalovirus. JLE 6: 46-65.

17. Girard B, Robinet M (1988) Cytomegalovirus and ocular pathology. Med Mal pp: 74-78. 
Citation: EL Fane M, Sodqi M, EL Rherbi A, Chakib A, Oulad Lahsen A, et al. (2016) Cytomegalovirus Disease in Patient with HIV Infection. J Antimicro 2: 108. doi:10.4172/2472-1212.1000108

Page 5 of 5

18. Girard PM, Katlama C, Pialoux G (2011) VIH Wolters Kluwer France, RueilMalmaison: Doin éditeurs p: 340.

19. Ranjan P, Gupta V, Goyal M, Dhawan S, Gupta P, et al. (2015) Cytomegalovirus infection in gastrointestinal tract: A case series of three patients and review of literature. J Dig Endosc 6: 134-138.

20. Périsse A, Sahuc P, Wybrecht D, Joubert C, Gaillard T, et al. (2014) Cerebral venous thrombosis: An unusual complication of acute cytomegalovirus infection. Rev Med Int 35: 268-270.

21. Balo K, Mihluedo H, Djagnikpo A, Koffi-Gue B (1997) Ocular complications in AIDS: what about cytomegalovirus retinitis ? Méd Afr Noire 44: 387-391.

22. Carmichael $A$ (2012) Cytomegalovirus and the eye. Eye Lond Engl 26: 237-240.

23. Bhaijee F, Subramony C, Tang SJ, Pepper DJ (2011) Human immunodeficiency virus-associated gastrointestinal disease: common endoscopic biopsy diagnoses. Pathol Res Int 2011: 247923.

24. Richard P, Le Tourneau A, Diebold J, Audouin J, Molina T (2007) Histopathological diagnosis of CMV infection in adult. RFL 388: 55-60.

25. Kaplan JE, Benson C, Holmes KH, Brooks JT, Pau A, et al. (2009) Guidelines for prevention and treatment of opportunistic infections in HIV infected adults and adolescents: recommendations from CDC, the National Institutes of Health, and the HIV Medicine Association of the Infectious Diseases Society of America. MMWR Recomm Rep 58 (RR-4): 1-207.

26. Wang HW, Kuo CJ, Lin WR, Hsu CM, Ho YP, et al. (2015) The clinical characteristics and manifestations of cytomegalovirus esophagitis. Dis Esophagus.

27. Jabs DA, Holbrook JT, Van Natta ML, Clark R, Jacobson MA, et al. (2005) Risk factors for mortality in patients with AIDS in the era of highly active antiretroviral therapy. Ophthalmology 112: 771-779.

28. Silva AC, De Oliveira PA, Vilas-Boas L, Fink MC, Pannuti CS, et al. (2010) Neurologic cytomegalovirus complications in patients with AIDS: retrospective review of 13 cases and review of the literature. Rev Inst Med trop S. Paulo 52: 305-310.
29. De Broucker T (2013) Neurological complications associated with human immunodeficiency virus (HIV) infection. Pra Neurol - FMC 4: 213-228.

30. Goplen DA, Liestol DK, Dunlop DO, Bruun DJ, Maehlen DJ (2001) Dementia in AIDS patients in Oslo; the role of HIV encephalitis and CMV encephalitis. Scand J Infect Dis 33: 755-758.

31. Heinzlef O, Roullet E (2005) Acute myelopathy. EMC - Neurologie 2: 526 - 543.

32. Huang L, Crothers K (2009) HIV- associated opportunistic pneumonias Respirol Carlton Vic 14: 474-485.

33. Chuganji E, Abe T, Kobayashi H, Nakano N, Kanai T, et al. (2014) Fatal Pulmonary Co-infection with Pneumocystis and Cytomegalovirus in a Patient with Acquired Immunodeficiency Syndrome. Intern Med 53: 1575-1578.

34. Arnold M, Itzikowitz R, Young B, Machoki SM, Hsiao NY, et al. (2015) Surgical manifestations of gastrointestinal cytomegalovirus infection in children: Clinical audit and literature review. J Pediatr Surg.

35. Morlat $P$ (2013) Prise en charge médicale des personnes vivant avec le $\mathrm{VIH} /$ Recommandations du groupe d'experts.

36. Michaux C, Morlat P, Bonnet F (2010) Cytomegalovirus and other herpes virus infections in systemic diseases. Presse Med 39: 34-41.

37. Stewart MW (2010) Optimal management of cytomegalovirus retinitis in patients with AIDS. Clin Ophthalmol 4: 285-299.

38. Jabs D, Ahuja A, Natta VM, Lyon A T, Yeh S, et al. (2015) Long-term Outcomes of Cytomegalovirus Retinitis in the Era of Modern Antiretroviral Therapy. Results from a United States Cohort. Ophthalmology.

39. Albert DM, Kulkarni AD, Azari AA (2015) Clinical Infectious Diseases, ( $\left.2^{\text {nd }} e d n\right)$, David Shlossberg by Cambridge University Press.

40. Jabs DA (2011) Cytomegalovirus retinitis and the acquired immunodeficiency syndrome-bench to bedside. Am J Ophthalmol 151: 198-216.

41. Janowicz DM, Johnson RM, Gupta SK (2005) Successful treatment of CMV ventriculitis immune reconstitution syndrome. J Neurol Neurosurg Psychiatry 76: 891-892. 